\title{
Is Antidepressant Treatment Associated with Reduced Cognitive Decline in Alzheimer's Disease?
}

\author{
Enrico Mossello ${ }^{a}$ Marta Boncinelli ${ }^{a}$ Veronica Caleri ${ }^{b}$ Maria Chiara Cavallini ${ }^{a}$ \\ Eliana Palermo ${ }^{a}$ Mauro Di Bari ${ }^{a}$ Sabrina Tilli ${ }^{a}$ Eva Sarcone $^{a}$ David Simoni $^{a}$ \\ Carlo Adriano Biagini ${ }^{b}$ Giulio Masotti ${ }^{a, c}$ Niccolò Marchionni ${ }^{a}$ \\ ${ }^{a}$ Department of Critical Care Medicine and Surgery, Unit of Gerontology and Geriatric Medicine, \\ University of Florence and Azienda Ospedaliero-Universitaria Careggi, Florence, ${ }^{\mathrm{b}}$ Azienda USL 3, \\ Unit of Geriatric Medicine, and 'Foundation 'Filippo Turati', Pistoia, Italy
}

\section{Key Words}

Dementia $\cdot$ Alzheimer's disease $\cdot$ Depression . Antidepressant drugs

\begin{abstract}
Background: Although antidepressant drugs (ATD) are frequently prescribed to patients with Alzheimer's disease (AD), their effect on cognitive status has been only rarely assessed. Methods: The impact of depressive symptoms and ATD on cognitive status was retrospectively assessed in 72 older $A D$ outpatients with mild-to-moderate cognitive impairment, treated with cholinesterase inhibitors, over a 9-month follow-up. Results: Compared to subjects without baseline depressive symptoms, those with symptoms who were continuously treated with ATD had less cognitive decline; those never treated, or not continuously treated despite baseline symptoms, had an intermediate trend. Such a protective action of ATD was, at least in part, independent of their action on depressive symptoms. Conclusion: These observations suggest that ATD may reduce cognitive decline in depressed older AD patients.

Copyright $\odot 2008$ S. Karger AG, Basel
\end{abstract}

() 2008 S. Karger AG, Basel $1420-8008 / 08 / 0254-0372 \$ 24.50 / 0$

Fax +41613061234 E-Mail karger@karger.ch www.karger.com

\section{Introduction}

Neuropsychiatric symptoms are present in about $60 \%$ of community-dwelling patients with different forms of dementia; in particular, depressive symptoms have been detected in as many as $25 \%$ of all demented patients [1] and in $20-50 \%$ of subjects diagnosed with Alzheimer's disease (AD) [2-4]. The impact of such symptoms on cognitive function in $\mathrm{AD}$ patients is uncertain. In some cross-sectional reports, AD patients with major depression had greater cognitive impairment than nondepressed patients [5], especially in the early stages of dementia [6], a result not confirmed by other studies [7]. Contrasting findings were reported in longitudinal studies, in which baseline depressive symptoms predicted either a faster [8] or a slower cognitive decline [9], or no effect at all [10].

Adding to these uncertainties, the clinical effects of pharmacologic treatment of depression associated with $\mathrm{AD}$ are controversial. Although a consensus exists that a treatment is usually indicated and that selective serotonin reuptake inhibitors (SSRI) are the first-line agents in this setting [11], this therapeutic recommendation is not sup- 
ported by conclusive evidence. Some randomized, placebo-controlled trials showed a beneficial effect of SSRI on mood status [12,13], which was not confirmed in another trial [14]. Data on cognitive outcomes are even more sparse. A randomized clinical trial suggested that antidepressants improved cognitive function in depressed subjects with dementia [15], whereas a subsequent study showed positive effects of these agents on functional, but not cognitive, status of depressed AD patients [16]. Moreover, the available evidence is further limited because studies had small sample sizes, considered only shortterm effect (6-12 weeks), and in most cases were conducted in patients not receiving cholinesterase inhibitors.

We conducted this real-world, longitudinal, retrospective study, to evaluate the effect of both depressive symptoms and antidepressant treatment on the timecourse of cognitive decline in older subjects affected by mild-to-moderate $\mathrm{AD}$, who were treated with cholinesterase inhibitors.

\section{Methods}

\section{Patients}

Medical records of patients consecutively referred to our AD outpatient clinic were reviewed to identify subjects who were diagnosed with AD according to NINCDS-ADRDA criteria [17] and scored $\geq 15 / 30$ at the Mini Mental State Examination (MMSE) [18] at their first evaluation. Further inclusion criteria were treatment with cholinesterase inhibitors (donepezil, rivastigmine or galantamine) and participation in 3- and 9-month follow-up visits.

\section{Clinical Assessment and Data Collection}

Comprehensive geriatric assessment, extended neuropsychological evaluation, blood testing (including thyroid hormones, folate and cobalamin), and brain neuroimaging (CT or MRI scan) were carried out at baseline (T0). Cognitive function was evaluated with MMSE, and global functional status with Katz's Activities of Daily Living (ADL) [19] and Lawton's Instrumental ADL (IADL) [20] scales. ADL score ranged from 0 to 6, depending on the number of activities the subject was able to perform independently. IADL score ranged from 0 to $100 \%$, depending on the proportion of chores the subject was still able to conduct, out of those usually performed before the onset of disease. Depressive and neuropsychiatric symptoms were rated with the 15 -item Geriatric Depression Scale (GDS) [21] and the Neuropsychiatric Inventory (NPI) [22], respectively. Comorbidity was measured with the Cumulative Illness Rating Scale (CIRS), which rates the severity of 12 organ diseases in five classes, from 'absent' to 'very severe' [23]; based on CIRS scores, 'complex comorbidity' was defined as the number of diseases coded as at least 'moderate'. The vascular component of cognitive decline was evaluated by Hachinski Ischemic Score (HIS) [24]. AD duration was estimated from the date of initial signs of cognitive decline, as reported by the caregiver. All participants were prescribed cholinesterase in- hibitors, while other treatments, including psychotropic drugs, were newly prescribed, withheld or maintained, based on clinical judgment. At baseline, depression (D+) was operationally diagnosed according to a GDS score $>5 / 15$ and/or ongoing antidepressant treatment; participants were judged to be non-depressed (D-) if their baseline GDS score was $\leq 5 / 15$ and they were not on antidepressants.

Patients were re-assessed at 3 (T1) and 9 (T2) months, when MMSE, ADL, IADL and GDS scales were administered again. Independently of their baseline GDS score, participants were further categorized according to antidepressant use throughout the study: those continuously treated with antidepressants up to the 9-month follow-up were defined as 'treated' ( $\operatorname{Tr}+$ ), while the remaining - including those who were prescribed antidepressants only for a part of the follow-up - were considered as 'untreated' ( $\mathrm{Tr}-$ ).

\section{Statistical Analysis}

Analyses were performed with SPSS 12.0.1 (SPSS Inc., Chicago, Ill., USA). Continuous variables, presented as mean \pm SEM, were compared between groups with ANOVA, using Bonferroni test for post-hoc analysis. Categorical variables were compared with Pearson's $\chi^{2}$ test. MMSE, ADL, IADL and GDS scores at T0, $\mathrm{T} 1$ and $\mathrm{T} 2$ were compared within groups with ANOVA for repeated measures. Changes in MMSE, ADL, IADL and GDS scores from baseline to $\mathrm{T} 1(\Delta \mathrm{T} 1=\mathrm{T} 1-\mathrm{T} 0)$ and $\mathrm{T} 2(\Delta \mathrm{T} 2=\mathrm{T} 2-\mathrm{T} 0)$ were compared between groups with ANOVA. Change in MMSE, ADL and IADL scores over time was further analyzed by multivariable linear regression equations, in which age, gender and baseline value of the dependent variable were included, together with depression and antidepressant treatment status (model 1), to adjust for confounding. A second set of equations was also built (model 2), where change in GDS score was added to the previous covariates. $\mathrm{p}<0.05$ was considered statistically significant.

\section{Results}

Baseline clinical characteristics of the 72 participants are reported in table 1 . As required in the inclusion criteria, all the participants were on cholinesterase inhibitors, represented by donepezil in 41 (57\%), rivastigmine in 24 (33\%), and galantamine in 7 (10\%). According to a GDS score $>5$ and/or ongoing antidepressant treatment, 39 (54\%) subjects were defined as D+. Of them, 24 were continuously maintained ( $\mathrm{Tr}+$ ) and 15 were not maintained ( $\mathrm{Tr}-$ ) on antidepressants from baseline up to the T2 follow-up. None of the participants initially judged as nondepressed (D-) received continuous antidepressant treatment throughout the 9-month observation period. Thus, according to baseline mood status and antidepressant treatment over time, the following 3 groups were identified: $\mathrm{D}+/ \mathrm{Tr}+(\mathrm{n}=24,33 \%), \mathrm{D}+/ \mathrm{Tr}-(\mathrm{n}=15,21 \%)$, and $\mathrm{D}-/ \operatorname{Tr}-(\mathrm{n}=33,46 \%)$. Twenty-one of the $\mathrm{D}+/ \mathrm{Tr}+$ subjects were already treated at baseline, for a mean treatment length before T0 of $22 \pm 12$ months (range 1-120 months), 
Table 1. Baseline clinical characteristics of the 72 study participants

\begin{tabular}{lc}
\hline Age, years & $78 \pm 0.8[62-93]$ \\
Females, $\mathrm{n}(\%)$ & $53(74)$ \\
Married, $\mathrm{n}(\%)$ & $35(48)$ \\
Education, years & $6.3 \pm 0.4[2-18]$ \\
Caregiver, $\mathrm{n}(\%)$ & $28(39)$ \\
$\quad$ Spouse & $40(56)$ \\
$\quad$ Child & $4(5)$ \\
$\quad$ Other & $20.7 \pm 0.4[15-28]$ \\
MMSE & $5.0 \pm 0.2[0-6]$ \\
ADL & $48.6 \pm 3.5[0-100]$ \\
IADL, (\%) & $4.2 \pm 0.4[0-14]$ \\
GDS & $18.1 \pm 1.4[0-48]$ \\
NPI & $1.9 \pm 0.2[0-5]$ \\
Complex comorbidity ${ }^{1}$ & $3.0 \pm 0.2[0-7]$ \\
HIS & $35 \pm 2[9-84]$ \\
AD duration, months & $28(39)$ \\
Antidepressant treatment, n (\%) & \\
\hline \multicolumn{2}{l}{ Continuous variables are expressed as mean \pm SEM [range]. } \\
$\quad$ MMSE = Mini-Mental State Examination; ADL = Activities of \\
Daily Living; IADL = Instrumental Activities of Daily Living; \\
GDS = Geriatric Depression Scale; NPI = Neuropsychiatric In- \\
ventory; HIS = Hachinski Ischemic Score; AD = Alzheimer's Dis- \\
ease. \\
$\quad$ Number of diseases coded as moderate to severe on the Cu- \\
mulative Illness Rating Scale. \\
\hline
\end{tabular}

Table 2. Baseline clinical characteristics, according to the presence/absence of depression (D+/D-) and to continuous antidepressant treatment during the follow-up period $(\mathrm{Tr}+/ \mathrm{Tr}-)$

\begin{tabular}{lcccc}
\hline & $\begin{array}{c}\mathrm{D}+/ \mathrm{Tr}+ \\
(\mathrm{n}=24)\end{array}$ & $\begin{array}{c}\mathrm{D}+/ \mathrm{Tr}- \\
(\mathrm{n}=15)\end{array}$ & $\begin{array}{c}\mathrm{D}-/ \mathrm{Tr}- \\
(\mathrm{n}=33)\end{array}$ & $\mathrm{p}$ \\
\hline Age, years & $77.1 \pm 1.3$ & $76.2 \pm 1.6$ & $79.1 \pm 1.1$ & 0.268 \\
Females, n (\%) & $16(67)$ & $13(87)$ & $24(73)$ & 0.382 \\
Married, n (\%) & $12(50)$ & $5(33)$ & $18(54)$ & 0.390 \\
Education, years & $6.2 \pm 0.8$ & $5.5 \pm 1.0$ & $6.8 \pm 0.7$ & 0.525 \\
Spouse caregiver, n (\%) & $11(46)$ & $4(27)$ & $13(39)$ & 0.460 \\
MMSE & $20.1 \pm 0.8$ & $21.5 \pm 1.0$ & $20.8 \pm 0.7$ & 0.561 \\
ADL & $4.9 \pm 0.3$ & $5.1 \pm 0.3$ & $5.1 \pm 0.2$ & 0.911 \\
IADL, (\%) & $47.9 \pm 6.2$ & $44.2 \pm 7.8$ & $51.1 \pm 5.3$ & 0.758 \\
GDS & $6.1 \pm 0.5$ & $6.5 \pm 0.7$ & $1.7 \pm 0.5$ & 0.000 \\
NPI & $19.6 \pm 2.5$ & $17.2 \pm 3.1$ & $17.4 \pm 2.1$ & 0.758 \\
Complex comorbidity & $1.7 \pm 0.3$ & $2.1 \pm 0.3$ & $2.0 \pm 0.2$ & 0.586 \\
HIS & $2.7 \pm 0.3$ & $3.3 \pm 0.4$ & $3 \pm 0.2$ & 0.431 \\
AD duration, months & $36 \pm 7$ & $40 \pm 8$ & $42 \pm 6$ & 0.762 \\
\hline
\end{tabular}

Continuous variables are expressed as mean \pm SEM.

MMSE = Mini-Mental State Examination; $\mathrm{ADL}=$ Activities of Daily Living; IADL = Instrumental Activities of Daily Living; GDS = Geriatric Depression Scale; NPI = Neuropsychiatric Inventory; HIS = Hachinski Ischemic Score; $\mathrm{AD}=$ Alzheimer's Disease.

${ }^{1}$ Number of diseases coded as moderate to severe on the $\mathrm{Cu}$ mulative Illness Rating Scale.

Table 3. MMSE, ADL, IADL and GDS score changes over time, by depression at baseline (D) and antidepressant treatment $(\mathrm{Tr})$

\begin{tabular}{|c|c|c|c|c|c|c|c|c|}
\hline & \multicolumn{2}{|l|}{ MMSE } & \multicolumn{2}{|l|}{$\mathrm{ADL}$} & \multicolumn{2}{|l|}{ IADL (\%) } & \multicolumn{2}{|l|}{ GDS } \\
\hline & $\Delta \mathrm{T} 1$ & $\Delta \mathrm{T} 2$ & $\Delta \mathrm{T} 1$ & $\Delta \mathrm{T} 2$ & $\Delta \mathrm{T} 1$ & $\Delta \mathrm{T} 2$ & $\Delta \mathrm{T} 1$ & $\Delta \mathrm{T} 2$ \\
\hline $\mathrm{D}+/ \mathrm{Tr}+$ & $1.6 \pm 0.5$ & $0.3 \pm 0.7$ & $-0.1 \pm 0.1$ & $-0.2 \pm 0.2$ & $-7.0 \pm 3.1$ & $-6.5 \pm 3.8$ & $-1.7 \pm 0.5$ & $-1.7 \pm 0.5$ \\
\hline $\mathrm{D}+/ \mathrm{Tr}-$ & $0.2 \pm 0.6$ & $0.0 \pm 0.8$ & $0.0 \pm 0.2$ & $-0.3 \pm 0.3$ & $-0.5 \pm 3.9$ & $-2.3 \pm 4.8$ & $-0.6 \pm 0.7$ & $-1.4 \pm 0.7$ \\
\hline $\mathrm{D}-/ \mathrm{Tr}-$ & $-0.6 \pm 0.4$ & $-1.9 \pm 0.6$ & $-0.2 \pm 0.1$ & $-0.6 \pm 0.2$ & $-7.0 \pm 2.6$ & $-11.6 \pm 3.2$ & $0.4 \pm 0.4$ & $0.4 \pm 0.4$ \\
\hline
\end{tabular}

Continuous variables are expressed as mean \pm SEM.

MMSE = Mini-Mental State Examination; $\mathrm{ADL}=$ Activities of Daily Living; $\mathrm{IADL}=$ Instrumental Activities of Daily Living; GDS = Geriatric Depression Scale.

whereas 3 were started on antidepressants at enrollment. Antidepressants were never prescribed in 4 out of 15 $\mathrm{D}+/ \mathrm{Tr}$ - participants $(27 \%)$, whereas the others were exposed to treatment only for part of the follow-up (7 months on average); antidepressants were withdrawn in 3 (20\%), due to adverse events (tremor in 1 participant; worsened cognition in 1 participant) or lack of efficacy (1 participant), and prescribed only later on after enrollment in 8 (53\%). These drugs were used also, for a limited time (5.5 months on average), in $6(18 \%)$ of the 33 participants initially judged as nondepressed (D-/Tr-).

The main baseline clinical characteristics were comparable across the three groups (table 2), with the exception of GDS score, which was as expected lower in the 
Fig. 1. Changes in Mini Mental State Examination (MMSE), Basic and Instrumental Activities of Daily Living (ADL, IADL), and Geriatric Depression Scale (GDS) score over time, by baseline GDS score and antidepressant treatment status. $\mathrm{D}-/ \mathrm{Tr}-=$ Non-depressed/untreated; $\mathrm{D}+/ \mathrm{Tr}-=$ depressed/untreated; $\mathrm{D}+/ \mathrm{Tr}+=$ depressed/ treated.

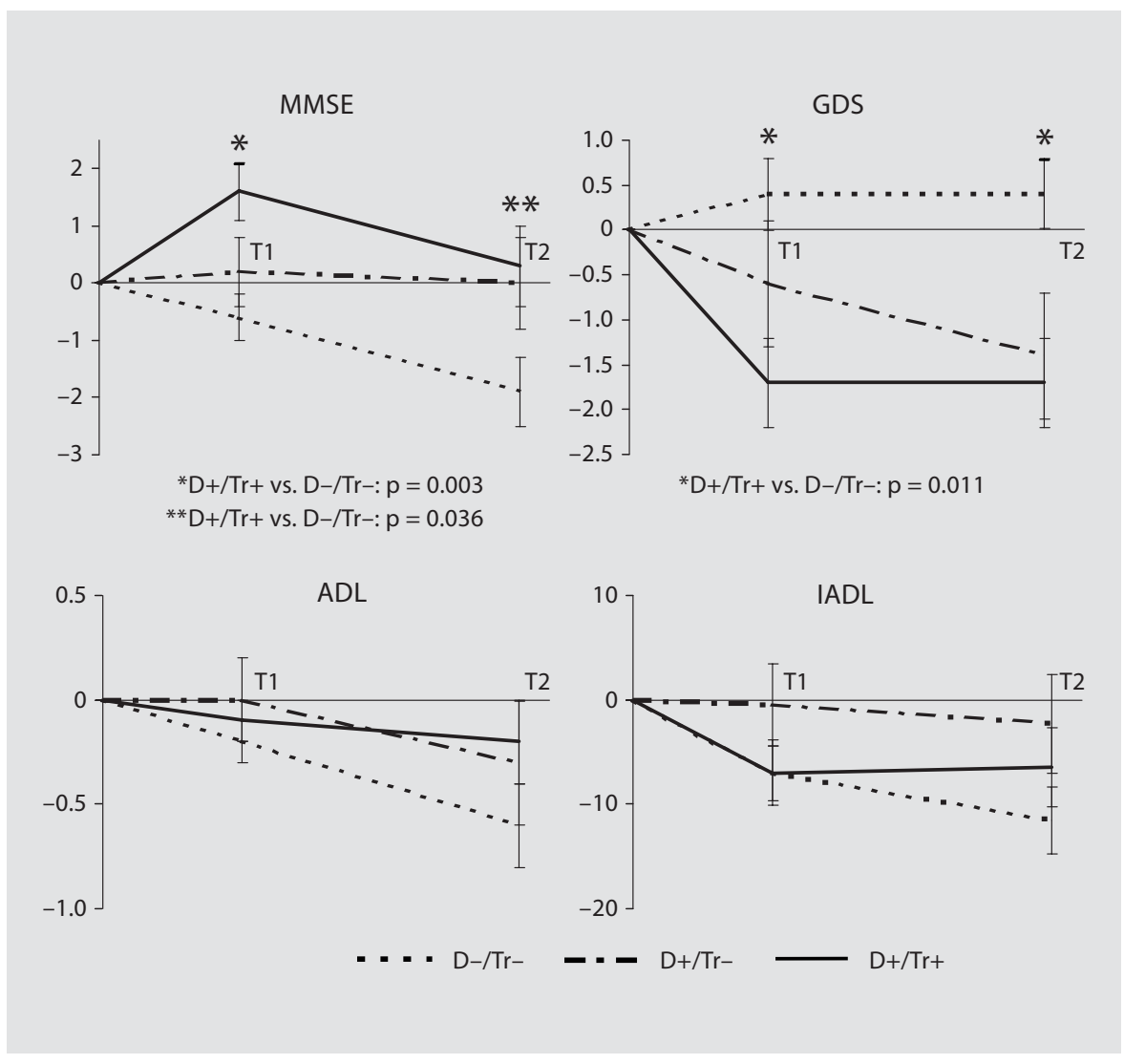

$\mathrm{D}-/ \mathrm{Tr}$ - group. The most frequently used antidepressants were SSRI, which were taken by $20(83 \%)$ of $\mathrm{D}+/ \mathrm{Tr}+$ subjects; mirtazapine was given in 2 cases, venlafaxine and trazodone in 1 case each.

\section{Longitudinal Analysis}

Changes in MMSE, GDS, ADL, and IADL scores over time are compared across the three groups in figure 1 and table 3. In $\mathrm{D}+/ \mathrm{Tr}+$ participants, MMSE score significantly increased $(p=0.004)$ from baseline to $T 1$, and remained substantially unchanged thereafter. No change in MMSE score was observed in $\mathrm{D}+/ \mathrm{Tr}$ - participants, while it declined significantly in $\mathrm{D}-/ \mathrm{Tr}$ - participants $(\mathrm{p}=0.002)$. In post-hoc analyses, MMSE score improved in $\mathrm{D}+/ \mathrm{Tr}+$ compared with $\mathrm{D}-/ \mathrm{Tr}$ - participants, but not with $\mathrm{D}+/ \mathrm{Tr}-$, at both $\mathrm{T} 1$ and T2. Similarly, GDS score decreased significantly at $\mathrm{T} 1(\mathrm{p}=0.008)$ and $\mathrm{T} 2(\mathrm{p}=$ $0.003)$ in $\mathrm{D}+/ \mathrm{Tr}+$ group, whereas it slightly increased in $\mathrm{D}-/ \mathrm{Tr}-$ and decreased in $\mathrm{D}+/ \mathrm{Tr}$ - groups over time. Posthoc analyses demonstrated that depressive symptoms decreased significantly in $\mathrm{D}+/ \mathrm{Tr}+$ group compared with $\mathrm{D}-/ \mathrm{Tr}-$ at both $\mathrm{T} 1$ and $\mathrm{T} 2$. Changes in ADL and IADL

Antidepressants and Cognitive Decline in $\mathrm{AD}$ scores were similar across groups at any point of followup.

Multivariable analyses confirmed the associations previously described between cognitive status changes and antidepressant treatment. Indeed, in a first multivariable linear regression model, adjusted for age, gender and baseline MMSE score (table 4), the increase in MMSE score was significantly greater in $\mathrm{D}+/ \mathrm{Tr}+$ compared with $\mathrm{D}-/ \mathrm{Tr}$ - group. After further adjusting for changes in GDS over time (model 2), the increase in MMSE score remained significantly greater in $\mathrm{D}+/ \mathrm{Tr}+$ at $\mathrm{T} 1$, and slightly greater $(\mathrm{p}=0.061)$ at T2. Depressive status and antidepressant treatment were not significantly associated with ADL and IADL score changes over time (data not shown).

\section{Discussion}

In this sample of older outpatients with mild-to-moderate $\mathrm{AD}$, all treated with cholinesterase inhibitors, antidepressant drug use was associated with an improved 
Table 4. Determinants of MMSE score change at 3 and 9 months (T1, T2): for each variable, B coefficient \pm SE from multiple linear regression models are reported

\begin{tabular}{|c|c|c|c|c|}
\hline & \multicolumn{2}{|l|}{ Model 1} & \multicolumn{2}{|l|}{ Model 2} \\
\hline & $\Delta \mathrm{T} 1$ & $\Delta \mathrm{T} 2$ & $\Delta \mathrm{T} 1$ & $\Delta \mathrm{T} 2$ \\
\hline Intercept & $\begin{array}{l}4.41 \pm 4.38 \\
p=0.318\end{array}$ & $\begin{array}{l}0.72 \pm 5.75 \\
p=0.901\end{array}$ & $\begin{array}{l}3.80 \pm 4.41 \\
\mathrm{p}=0.392\end{array}$ & $\begin{array}{c}-1.34 \pm 5.83 \\
p=0.815\end{array}$ \\
\hline Age & $\begin{array}{c}-0.01 \pm 0.05 \\
p=0.913\end{array}$ & $\begin{array}{c}-0.03 \pm 0.06 \\
p=0.595\end{array}$ & $\begin{array}{c}-0.01 \pm 0.05 \\
p=0.937\end{array}$ & $\begin{array}{c}-0.03 \pm 0.06 \\
p=0.688\end{array}$ \\
\hline Gender (females vs. males) & $\begin{array}{c}-0.75 \pm 0.75 \\
p=0.324\end{array}$ & $\begin{array}{c}-0.37 \pm 0.99 \\
p=0.711\end{array}$ & $\begin{array}{c}-0.66 \pm 0.75 \\
p=0.386\end{array}$ & $\begin{array}{c}-0.21 \pm 0.98 \\
p=0.828\end{array}$ \\
\hline MMSE at T0 & $\begin{array}{c}-0.13 \pm 0.09 \\
p=0.148\end{array}$ & $\begin{array}{l}0.10 \pm 0.12 \\
p=0.386\end{array}$ & $\begin{array}{c}-0.12 \pm 0.09 \\
p=0.205\end{array}$ & $\begin{array}{l}0.16 \pm 0.12 \\
p=0.201\end{array}$ \\
\hline $\begin{array}{l}\text { Depressive/treatment status } \\
\quad(\mathrm{D}+/ \mathrm{Tr}+\mathrm{vs} . \mathrm{D}-/ \mathrm{Tr}-)\end{array}$ & $\begin{array}{l}2.09 \pm 0.67 \\
p=0.003\end{array}$ & $\begin{array}{l}2.19 \pm 0.88 \\
p=0.015\end{array}$ & $\begin{array}{l}1.84 \pm 0.71 \\
\mathrm{p}=0.011\end{array}$ & $\begin{array}{l}1.74 \pm 0.92 \\
p=0.061\end{array}$ \\
\hline GDS score change & - & - & $\begin{array}{c}-0.13 \pm 0.11 \\
p=0.269\end{array}$ & $\begin{array}{c}-0.24 \pm 0.15 \\
p=0.116\end{array}$ \\
\hline
\end{tabular}

$\mathrm{D}+/ \mathrm{Tr}+=$ Depressed/treated; D-/Tr- = non-depressed/untreated.

cognitive performance after 3 months, and less overall decline at 9 months.

Our comprehensive definition of depression, based on GDS and/or antidepressant drug use, aimed at including also subjects in whom depressive symptoms might have subsided because of treatment. The diagnostic value of GDS in untreated participants might be criticized for several reasons. A nosographic approach might appear more valid, at least in theory: however, depressive disorders in $\mathrm{AD}$ have clinical peculiarities, limiting the applicability of DSM or ICD criteria $[25,26]$. Other criteria have been recently proposed - unfortunately after this study was designed - to recognize depression in the context of $\mathrm{AD}$ [27]; yet their validity is so far unsupported by robust evidence. Furthermore, recently published data show that the retrospective application of these novel criteria nearly doubled the prevalence of depressive disorders compared with DSM, and that the concordance among different sets of criteria for depression in $\mathrm{AD}$ was very poor [26]. Therefore, a dimensional approach to depressive symptoms based on rating scales, which has the clear advantage of feasibility in clinical practice, may be considered valid to assess the emotional profile in this context [28]. While scales have been specifically designed for this purpose [29], the GDS, initially validated in older, cognitively intact subjects, proved reliable also in patients with mild-to-moderate dementia and MMSE score $\geq 15 / 30$ [30], as those in our study.
Baseline cognitive performance and functional status were similar in depressed and non-depressed subjects. This observation is consistent with previous studies, reporting that depression does not affect cognitive function in mild AD [7]. Moreover, in this study clinically significant depressive symptoms were usually treated before enrollment, to rule out possible 'pseudo-dementia' cases: this might have attenuated a negative effect of depression on baseline cognitive and functional performance.

A subgroup of 24 subjects treated with antidepressants up to the 9-month follow-up $(\mathrm{D}+/ \mathrm{Tr}+)$ was selected retrospectively, with the aim of analyzing the effect of a sufficiently prolonged exposure to treatment. Their MMSE score increased significantly from baseline to the 3month follow-up and stabilized thereafter, while it progressively declined in non-depressed, untreated subjects (D-/Tr-group); the between-group difference remained significant also after adjustment for age, gender, and baseline MMSE score in multivariable analysis. This finding paralleled a significant decrease in GDS score from baseline in $\mathrm{D}+/ \mathrm{Tr}+$ participants, compared with those in the $\mathrm{D}-/ \mathrm{Tr}-$ group. The intermediate trend observed in $\mathrm{D}+/ \mathrm{Tr}-$ for MMSE and GDS score changes might be explained by the exposure of $73 \%$ of these patients to antidepressant treatment for part of the followup. This speculation is supported by a supplementary analysis, where data from $\mathrm{D}+/ \mathrm{Tr}+$ and $\mathrm{D}+/ \mathrm{Tr}-$ groups 
were pooled, which confirmed a significant difference between the entire $\mathrm{D}+$ group and $\mathrm{D}-/ \mathrm{Tr}$ - for change over time in both MMSE (D+: $\Delta \mathrm{T} 11.1 \pm 0.4, \mathrm{p}=0.005 \mathrm{vs}$. $\mathrm{D}-/ \mathrm{Tr}-; \Delta \mathrm{T} 20.2 \pm 0.5, \mathrm{p}=0.007$ vs. $\mathrm{D}-/ \mathrm{Tr}-)$ and GDS $(\mathrm{D}+\mathrm{T} 1-1.3 \pm 0.5, \mathrm{p}=0.007$ vs. $\mathrm{D}-/ \mathrm{Tr}-; \mathrm{T} 2-1.6 \pm$ $0.5, \mathrm{p}=0.002$ vs. $\mathrm{D}-/ \mathrm{Tr}-)$ scores.

The adjusted difference in MMSE score change between $\mathrm{D}+/ \mathrm{Tr}+$ and $\mathrm{D}-/ \mathrm{Tr}$ - group averaged 2 points after 9 months. Although the clinical meaning of this difference might be questioned, it should be emphasized that a Cochrane meta-analysis of randomized clinical trials of cholinesterase inhibitors reported treatment effects of similar magnitude (1.4 points over 6-12 months) [31]. Moreover, even a minimal decline in MMSE score in dementia has been associated with a significant increase in the cost of care and in the risk of institutionalization [32].

Early AD patients with depression have been reported to have worse cognitive performances than nondepressed patients with a similar extent of neuropathologic lesions [6]; similarly, depression has been also associated with a partially reversible cognitive decline in older subjects without dementia [33]. Therefore, a decrease in depressive symptoms might improve cognitive function in $\mathrm{AD}$ patients. This hypothesis is consistent with the results of two randomized trials reporting a positive effect of antidepressant treatment on cognitive function in $\mathrm{AD}$ patients [15, 34]; nevertheless, other studies failed to confirm these findings $[16,35]$. However, in the present study, the difference in MMSE score between $\mathrm{D}+/ \mathrm{Tr}+$ and $\mathrm{D}-/ \mathrm{Tr}$ - participants remained significant also when changes in GDS over time were included in the multivariable model, suggesting that better preservation of cognitive function in $\mathrm{D}+/ \mathrm{Tr}+$ group was partially independent of the reduction in depressive symptoms, at least through the 3-month follow-up. A direct cognitive benefit of SSRI, which accounted for more than $80 \%$ of prescribed antidepressants in this study, is consistent with neurobiological data, linking the serotoninergic system to cognitive function in $\mathrm{AD}$ [36]. Alternatively, the results observed might be due to a positive interaction, involving either pharmacokinetic or pharmacodynamic mechanisms, between antidepressant and cholinergic drugs. Inhibition of cytochrome P-450 by some antidepressants, such as paroxetine [37], may indeed increase plasma levels of cholinergic drugs. Moreover, serotoninergic and cholinergic drugs might act synergistically to improve cognitive function, as observed in preclinical models $[38,39]$ and suggested by preliminary clinical studies of $\mathrm{AD}$ patients [40]. Hence, randomized clinical trials aiming at evaluating the effect of this association would be welcome.

Antidepressant treatment status did not affect change of functional status over time. This can be explained both by the pre-enrollment treatment of severe, potentially disabling, depressive symptoms in most patients, and by the extent of comorbidity in our participants, which might have hindered functional preservation, in spite of a lesser cognitive decline.

Study limitations should be acknowledged, primarily due to its observational design, which is intrinsically weaker to assess causality than are randomized clinical trials. First, since the choice to continue antidepressant treatment was taken on a clinical basis, $\mathrm{D}+/ \mathrm{Tr}+$ group likely included patients who benefited from antidepressant drugs and did not report significant adverse events, so that the observed results might apply only to responders to treatment. However, only 3 of $15 \mathrm{D}+/ \mathrm{Tr}$ - patients were discontinued due to lack of response or to an adverse event, which was worsened cognition in only one; thus, it is unlikely that this has significantly biased our findings.

Second, the reduced cognitive decline observed in $\mathrm{D}+/ \mathrm{Tr}+$ group might be due to depression itself, rather than to antidepressant treatment. This hypothesis is consistent with the results reported by Janzing et al. [9] in a small observational study of subjects with mild dementia, in whom the number of depressive symptoms was inversely related to cognitive decline over 12 months, independent of changes in mood status. However, this inverse relationship between depression and cognitive outcome is not supported by epidemiological and neuropathological studies [41, 42] and is contradicted by other clinical investigations suggesting an opposite association [8]. Moreover, Janzing's study did not take into account the possible effect of treatment.

As a further limitation, the duration of antidepressant treatment before enrollment varied widely. However, this should not have influenced the results, as treatment length before enrollment was not significantly correlated to MMSE score change in $\mathrm{D}+/ \mathrm{Tr}+$ group (data not shown). Moreover, different classes of antidepressants were used. Yet, as the majority of patients were treated with SSRI and all antidepressants prescribed have a serotoninergic effect (although nonselective), we hypothesize the involvement of the serotoninergic action in the differences observed between groups.

Finally, compared with other instruments developed to assess patients longitudinally, the MMSE is definitely less sensitive. However, this test has had numerous research applications, including various RCTs of AD pa- 
tients [31], which document its satisfactory ability to detect changes in cognitive performance over time $[43,44]$. Moreover, we would speculate that the use of a more sensitive cognitive evaluation might have shown an even larger difference between groups.

We conclude that, in this sample of older subjects with mild-to-moderate $\mathrm{AD}$, all treated with cholinesterase inhibitors, antidepressant treatment was associated with less mid-term cognitive decline. Therefore, depressive symptoms may represent a clinically valuable target for treatment in the context of the multidimensional assessment and management of older patients with $\mathrm{AD}$, with the aim of better preserving their cognitive performance. This intriguing hypothesis needs to be confirmed in randomized trials of adequate design, sample size, and duration.

\section{References}

$>1$ Lyketsos CG, Steinberg M, Tschanz JT, Norton MC, Steffens DC, Breitner JC: Mental and behavioral disturbances in dementia: findings from the Cache County Study on Memory in Aging. Am J Psychiatry 2000; 157:708-714.

$\checkmark 2$ Migliorelli R, Teson A, Sabe L, Petracchi M, Leiguarda R, Starkstein SE: Prevalence and correlates of dysthymia and major depression among patients with Alzheimer's disease. Am J Psychiatry 1995;152:37-44.

-3 Zubenko GS, Zubenko WN, McPherson S, Spoor E, Marin DB, Farlow MR, Smith GE, Geda YE, Cummings JL, Petersen RC, Sunderland T: A collaborative study of the emergence and clinical features of the major depressive syndrome of Alzheimer's disease. Am J Psychiatry 2003;160:857-866.

$\checkmark 4$ Lyketsos CG, Olin J: Depression in Alzheimer's disease: overview and treatment. Biol Psychiatry 2002;52:243-252.

5 Lyketsos CG, Steele C, Baker L, Galik E, Kopunek S, Steinberg M, Warren A: Major and minor depression in Alzheimer's disease: prevalence and impact. J Neuropsychiatry Clin Neurosci 1997;9:556-561.

$\checkmark 6$ Milwain EJ, Nagy Z: Depressive symptoms increase the likelihood of cognitive impairment in elderly people with subclinical Alzheimer pathology. Dement Geriatr Cogn Disord 2005;19:46-50.

7 Powlishta KK, Storandt M, Mandernach TA, Hogan E, Grant EA, Morris JC: Absence of effect of depression on cognitive performance in early-stage Alzheimer disease. Arch Neurol 2004;61:1265-1268.

$>8$ Shim YS, Yang DW: Depression as prognostic factor: 6 months follow-up in a geriatric institution. Arch Gerontol Geriatr 2006;43: 277-283.

-9 Janzing JG, Naarding P, Eling P: Depressive symptoms predict slow cognitive decline in mild dementia. Dement Geriatr Cogn Disord 2005;20:77-81.

-10 Starkstein SE, Chemerinski E, Sabe L, Kuzis G, Petracca G, Teson A, Leiguarda R: Prospective longitudinal study of depression and anosognosia in Alzheimer's disease. Br J Psychiatry 1997;171:47-52.
11 Caltagirone C, Bianchetti A, Di Luca M, Mecocci P, Padovani A, Pirfo E, Scapicchio P, Senin U, Trabucchi M, Musicco M: Guidelines for the treatment of Alzheimer's disease from the Italian Association of Psychogeriatrics. Drugs Aging 2005;22(suppl 1):1-26.

12 Nyth AL, Gottfries CG: The clinical efficacy of citalopram in treatment of emotional disturbances in dementia disorders: a Nordic multicentre study. Br J Psychiatry 1990;157: 894-901.

13 Lyketsos CG, DelCampo L, Steinberg M, Miles Q, Steele CD, Munro C, Baker AS, Sheppard JM, Frangakis C, Brandt J, Rabins PV: Treating depression in Alzheimer disease: efficacy and safety of sertraline therapy, and the benefits of depression reduction: the DIADS. Arch Gen Psychiatry 2003;60: 737-746.

14 Petracca GM, Chemerinski E, Starkstein SE: A double-blind, placebo-controlled study of fluoxetine in depressed patients with Alzheimer's disease. Int Psychogeriatr 2001;13: 233-240.

15 Nyth AL, Gottfries CG, Lyby K, Smedegaard-Andersen L, Gylding-Sabroe J, Kristensen M, Refsum HE, Ofsti E, Eriksson S, Syversen S: A controlled multicenter clinical study of citalopram and placebo in elderly depressed patients with and without concomitant dementia. Acta Psychiatr Scand 1992;86:138-145.

16 Munro CA, Brandt J, Sheppard JM, Steele CD, Samus QM, Steinberg M, Rabins PV, Lyketsos CG: Cognitive response to pharmacological treatment for depression in Alzheimer disease: secondary outcomes from the depression in Alzheimer's disease study (DIADS). Am J Geriatr Psychiatry 2004;12: 491-498.

17 McKhann G, Drachman D, Folstein M, Katzman R, Price D, Stadlan EM: Clinical diagnosis of Alzheimer's disease: report of the NINCDS-ADRDA Work Group under the auspices of Department of Health and Human Services Task Force on Alzheimer's Disease. Neurology 1984;34:939-944.

18 Folstein MF, Folstein SE, McHugh PR: 'Minimental state': a practical method for grading the cognitive state of patients for the clinician. J Psychiatr Res 1975;12:189-198.
19 Katz S, Ford AB, Moskowitz RW, Jackson BA, Jaffe MW: Studies of illness in the aged. The index of ADL: a standardized measure of biological and psychosocial function. JAMA 1963;185:914-919.

20 Lawton MP, Brody EM: Assessment of older people: self-maintaining and instrumental activities of daily living. Gerontologist 1969; 9:179-186.

21 Yesavage JA, Brink TL, Rose TL, Lum O, Huang V, Adey M, Leirer VO: Development and validation of a geriatric depression screening scale: a preliminary report. J Psychiatr Res 1982;17:37-49.

22 Cummings JL: The Neuropsychiatric Inventory: assessing psychopathology in dementia patients. Neurology 1997;48:S10-S16.

23 Parmelee PA, Thuras PD, Katz IR, Lawton MP: Validation of the Cumulative Illness Rating Scale in a geriatric residential population. J Am Geriatr Soc 1995;43:130-137.

24 Hachinski VC, Iliff LD, Zilhka E, Du Boulay GH, McAllister VL, Marshall J, Russell RW, Symon L: Cerebral blood flow in dementia. Arch Neurol 1975;32:632-637.

25 Olin JT, Katz IR, Meyers BS, Schneider LS, Lebowitz BD: Provisional diagnostic criteria for depression of Alzheimer disease: rationale and background. Am J Geriatr Psychiatry 2002;10:129-141.

26 Vilalta-Franch J, Garre-Olmo J, Lopez-Pousa S, Turon-Estrada A, Lozano-Gallego M, Hernandez-Ferrandiz M, Pericot-Nierga I, Feijoo-Lorza R: Comparison of different clinical diagnostic criteria for depression in Alzheimer disease. Am J Geriatr Psychiatry 2006;14:589-597.

27 Olin JT, Schneider LS, Katz IR, Meyers BS, Alexopoulos GS, Breitner JC, Bruce ML, Caine ED, Cummings JL, Devanand DP, Krishnan KR, Lyketsos CG, Lyness JM, Rabins PV, Reynolds CF III, Rovner BW, Steffens DC, Tariot PN, Lebowitz BD: Provisional diagnostic criteria for depression of Alzheimer disease. Am J Geriatr Psychiatry 2002;10:125-128.

-28 Bungener C, Jouvent R, Derouesne C: Affective disturbances in Alzheimer's disease. J Am Geriatr Soc 1996;44:1066-1071. 
29 Alexopoulos GS, Abrams RC, Young RC, Shamoian CA: Cornell Scale for Depression in Dementia. Biol Psychiatry 1988;23:271284.

30 McGivney SA, Mulvihill M, Taylor B: Validating the GDS depression screen in the nursing home. J Am Geriatr Soc 1994;42: 490-492.

31 Birks J: Cholinesterase inhibitors for $\mathrm{Alz}$ heimer's disease. Cochrane Database Syst Rev 2006;CD005593.

>32 Wolstenholme J, Fenn P, Gray A, Keene J, Jacoby R, Hope T: Estimating the relationship between disease progression and cost of care in dementia. Br J Psychiatry 2002;181:3642.

-33 Butters MA, Becker JT, Nebes RD, Zmuda MD, Mulsant BH, Pollock BG, Reynolds CF III: Changes in cognitive functioning following treatment of late-life depression. Am J Psychiatry 2000;157:1949-1954.

34 Roth M, Mountjoy CQ, Amrein R: Moclobemide in elderly patients with cognitive decline and depression: an international double-blind, placebo-controlled trial. $\mathrm{Br} \mathrm{J}$ Psychiatry 1996;168:149-157.
5 Petracca G, Teson A, Chemerinski E, Leiguarda R, Starkstein SE: A double-blind placebo-controlled study of clomipramine in depressed patients with Alzheimer's disease. J Neuropsychiatry Clin Neurosci 1996;8: 270-275.

36 Lai MK, Tsang SW, Alder JT, Keene J, Hope T, Esiri MM, Francis PT, Chen CP: Loss of serotonin 5-HT2A receptors in the postmortem temporal cortex correlates with rate of cognitive decline in Alzheimer's disease. Psychopharmacology (Berl) 2005;179:673677.

37 Bentue-Ferrer D, Tribut O, Polard E, Allain $\mathrm{H}$ : Clinically significant drug interactions with cholinesterase inhibitors: a guide for neurologists. CNS Drugs 2003;17:947-963.

38 Dringenberg HC, Zalan RM: Serotonin-dependent maintenance of spatial performance and electroencephalography activation after cholinergic blockade: effects of serotonergic receptor antagonists. Brain Res 1999;837: 242-253.

39 Dringenberg HC, Diavolitsis P: Electroencephalographic activation by fluoxetine in rats: role of $5-\mathrm{HT}(1 \mathrm{~A})$ receptors and enhancement of concurrent acetylcholinesterase inhibitor treatment. Neuropharmacology $2002 ; 42: 154-161$.
40 Bragin V, Chemodanova M, Dzhafarova N, Bragin I, Czerniawski JL, Aliev G: Integrated treatment approach improves cognitive function in demented and clinically depressed patients. Am J Alzheimers Dis Other Demen 2005;20:21-26.

41 Ownby RL, Crocco E, Acevedo A, John V, Loewenstein D: Depression and risk for Alzheimer disease: systematic review, metaanalysis, and metaregression analysis. Arch Gen Psychiatry 2006;63:530-538.

42 Rapp MA, Schnaider-Beeri M, Grossman HT, Sano M, Perl DP, Purohit DP, Gorman JM, Haroutunian V: Increased hippocampal plaques and tangles in patients with Alzheimer disease with a lifetime history of major depression. Arch Gen Psychiatry 2006; 63:161-167.

43 Mossello E, Boncinelli M: Mini-Mental State Examination: a 30-year story. Aging Clin Exp Res 2006;18:271-273.

44 Tombaugh TN, McIntyre NJ: The mini-mental state examination: a comprehensive review. J Am Geriatr Soc 1992;40:922-935. 